\title{
Oportunidades para el éxito de los modelos de retención de granos en Nicaragua
}

\author{
Selmira Flores Cruz ${ }^{1}$ \\ 1. investigadora en comercio y género Nitlapán. Universidad Centroamericana (UCA). Apartado 69. Managua, Nicaragua. \\ e-mail: comercio@ns.uca.edu.ni
}

ESTE ARTíCULO ANALIZA LOS MODELOS DE RETENCIÓN DE GRANOS (maíz) que tienen el propósito de evitar pérdidas a los productores por bajos precios. Estas experiencias de comercialización se ponen en marcha con buenos deseos, guiados por el optimismo y la necesidad de generar cambios, pero no siempre parten de la dinámica y las reglas establecidas en el comercio de granos. Pregunta central: ¿Qué hace exitoso a un modelo de retención de granos para generar valor? Hipótesis: "El éxito está influenciado por la capacidad de aprendizaje e innovación organizacional en el establecimiento de alianzas estratégicas en el mercado, más que en obtener mejor precio". Método utilizado: Estudio de casos analizando la experiencia de La Unión de Campesinos Organizados de San Dionisio en Matagalpa (UCOSD), Empresa Cooperativa de Granos (ECOGRANOS) también de San Dionisio y La Empresa de Granos de Jalapa (EGRANOJAL).El trabajo comienza revisando el comportamiento de la producción de maíz en el área centroamericana en los últimos años; sigue una síntesis sobre la relación entre oferta y demanda en el país; y concluye analizando las experiencias de retención de granos.

Palabras claves: maíz-mercado, producción, regulación del comercio

\section{El maíz en Centroamérica}

El maíz constituye un producto de consumo básico para los centroamericanos. Guatemala es el mayor productor de la región, aunque a partir de $1998 \mathrm{su}$ superficie en área descendió considerablemente. Costa Rica mantiene una tendencia decreciente en superficie cultivada, igual que Honduras. El Salvador se mantiene relativamente en la misma área productiva y Nicaragua muestra crecimiento (cuadro 1). 
Cuadro 1. Área sembrada de maíz en Centroamérica por año (hectáreas)

\begin{tabular}{|l|r|r|r|r|r|}
\hline \multicolumn{1}{|c|}{ País } & \multicolumn{1}{c|}{$\mathbf{1 9 9 8}$} & \multicolumn{1}{c|}{$\mathbf{1 9 9 9}$} & $\mathbf{2 0 0 0}$ & \multicolumn{1}{c|}{$\mathbf{2 0 0 1}$} & \multicolumn{1}{c|}{$\mathbf{2 0 0 2}$} \\
\hline Nicaragua & 251,632 & 251,938 & 325,143 & 317,090 & 323,253 \\
\hline Honduras & 446,455 & 389,831 & 371,594 & 344,225 & 320,000 \\
\hline El Salvador & 295,400 & 263,410 & 259,259 & 294,105 & 294,105 \\
\hline Costa Rica & 16,002 & 13,215 & 10,216 & 7,680 & 12,400 \\
\hline Guatemala & 628,906 & 589,750 & 591,500 & 592,900 & 620,000 \\
\hline
\end{tabular}

Fuente: FAO con datos de FAOSTAT

El país que menos maíz produce es Costa Rica. Honduras y El Salvador se mantienen relativamente en el mismo nivel de producción, al igual que Guatemala, que presenta de manera estable un volumen de producción ligeramente superior al millón de toneladas métricas. En Nicaragua, el comportamiento ha sido ascendente, incrementando en un poco más de 100,000 toneladas la producción entre los años 1998 y 2002, como puede verse en el cuadro .

Cuadro 2. Volumen de maíz seco cosechado (producción: toneladas métricas)

\begin{tabular}{|l|r|r|r|r|r|}
\hline \multicolumn{1}{|c|}{ País } & $\mathbf{1 9 9 8}$ & $\mathbf{1 9 9 9}$ & $\mathbf{2 0 0 0}$ & $\mathbf{2 0 0 1}$ & \multicolumn{1}{c|}{$\mathbf{2 0 0 2}$} \\
\hline Nicaragua & 300,469 & 290,777 & 412,195 & 419,863 & 414,137 \\
\hline Costa Rica & 28,408 & 23,323 & 18,502 & 12,734 & 22,000 \\
\hline El Salvador & 563,095 & 659,760 & 582,967 & 564,977 & 564,977 \\
\hline Honduras & 471,327 & 477,511 & 533,598 & 516,079 & 480,000 \\
\hline Guatemala & $1,068,779$ & $1,024,860$ & $1,053,550$ & $1,091,480$ & $1,100,000$ \\
\hline
\end{tabular}

Fuente: FAO, con datos de FAOSTAT

Respecto a las exportaciones, la tendencia más decreciente la muestra Guatemala, que descendió sus exportaciones e incrementó sus importaciones, equiparándose a Costa Rica, que es el mayor importador de maíz de la región. La ilustración 1 presenta a Nicaragua de manera estable en su nivel de importaciones, a diferencia de los otros países que muestran una tendencia creciente.

Importaciones de maíz en CA

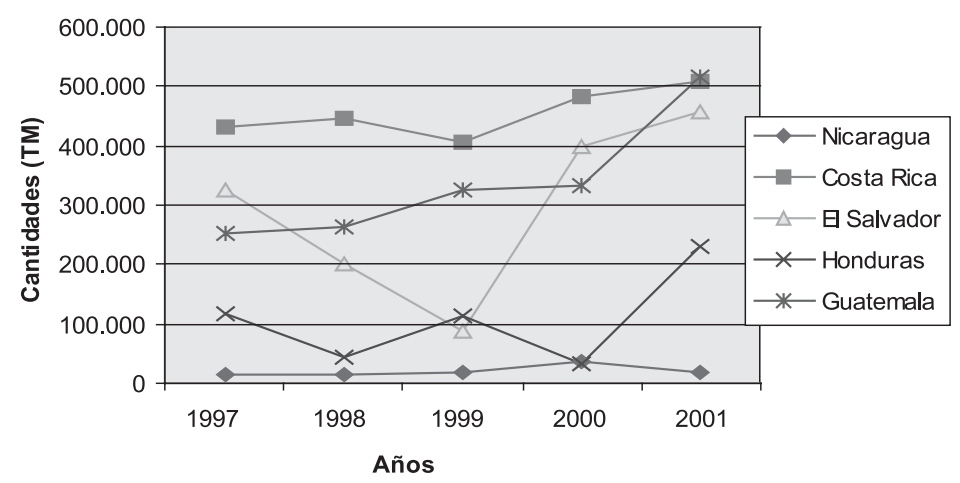

Ilustración 1. Importaciones de maíz en Centroamérica. 
En resumen, el mercado de granos para Centroamérica presenta, en los últimos años, irregularidades en la relación, producción, importaciones y exportaciones. Se evidencia una tendencia ha disminuir el área de producción con dificultades de recuperación de los niveles del año 98; y una tendencia creciente a las importaciones de maíz, con excepción de Nicaragua. Datos que permiten perfilar una posición favorable de Nicaragua para continuar produciendo y exportando granos al resto de los países de la región. No obstante, el mercado de los granos es bastante riesgoso en el contexto del Tratado de Libre Comercio.

\section{Oferta y demanda de maíz en Nicaragua}

La oferta de maíz aumentó de 4,375,000 quintales en el ciclo productivo 90-91 a 9,100,00 quintales estimados para el ciclo productivo 2002-2003, (ver ilustración 2).

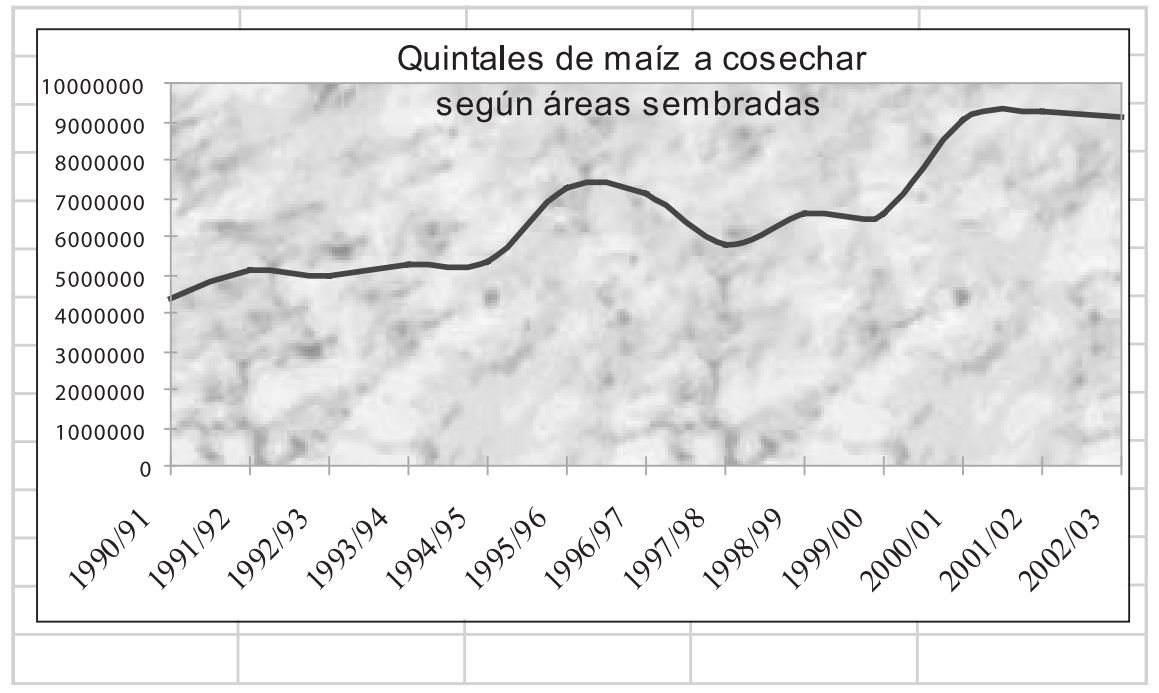

llustración 2. Quintales de maíz a cosechar según áreas de siembra.

Aunque con menos recursos dirigidos a la producción, el incremento en los últimos años parece estar asociado a varios factores, entre ellos: i) el efecto de los programas de rehabilitación post-Mitch, implementados por Organizaciones no Gubernamentales que lograron captar recursos de la cooperación internacional y distribuir semilla de manera gratuita. ii) el antecedente de un año bueno en los precios del maíz, estimula a los productores a un incremento de áreas de cultivo, sin suficiente entendimiento de las causas de estos comportamientos atípicos de los precios, cuyo efecto se reflejará nuevamente en una caída de precios por sobreproducción. iii) la incidencia del Programa libra por libra llevado a cabo por el gobierno, que en el ciclo productivo 2002-2003 distribuyó 23,000 quintales de semilla certificada para sembrar unas 120,000 manzanas.

La oferta se complementa con importaciones, aunque dirigidas principalmente a las granjas avícolas, y el maíz que se compra es una variedad que el país no produce (maíz amarillo). En los últimos años, las importaciones de maíz llegaron de siete países: Estados Unidos, Argentina, México, Costa Rica, Honduras, El Salvador y Guatemala. Se importó maíz amarillo, 
blanco, para semilla y otrosi. De Estados Unidos provino la mayor cantidad: un total de 2,537,990 quintales, de los que el 90.24\% fue maíz amarillo y el 9.76\%, maíz blanco.

Del total de maíz amarillo importado entre 1990-2003, el 75\% vino de Estados Unidos; el 18\%, de Argentina; y el 7.12\%, de México. De estos países, Estados Unidos y Argentina han mantenido sus exportaciones a Nicaragua de manera regular; no así México. Las importaciones de maíz blanco a Nicaragua provienen del área Centroamericana: de El Salvador llegó el 56\% (238,342 quintales) entre 1998-2003; de Honduras llegó el 30\% del maíz; y el resto, vino de Guatemala y Costa Rica, con el 7 \% respectivamente.

Por el lado de la demanda, la mayor parte se concentra en el sector doméstico y en la micro y pequeña industria. Se demanda grano seco para distintos fines: elaboración de productos alimenticios para consumo humano: tortillas, nacatamales, tamales, rosquillas u otras formas de pan y diferentes bebidas (chicha, pozol, pinolillo), entre otros. La demanda también se da sobre el grano seco por parte de empresas que fabrican concentrado para alimentación animal, y también por otros consumidores que destinan el maíz como grano entero para la alimentación de aves de corral o cerdos.

La micro y pequeña industria artesanal también procesa maíz para diferentes fines: cereales o productos como rosquillas. La ciudad de Somoto, por ejemplo, consume anualmente 2,400 quintales aproximados entre 17 centros de producción de rosquillas (Alvarado y Rivera, 2003). Si este consumo se multiplica por los otros centros de producción de rosquillas (Yalagüina, La Esperanza, Darío, Rivas, etc.), la demanda de este sector aumenta, pero no se percibe por su aparente dispersión.

Otros datos de consumo local revelan la importancia del grano. El municipio de Estelí cuenta con 90 micro industrias artesanales cuyo insumo es el maíz; de ellas, 59 producen tortillas diariamente y 28, nacatamales (CURN-Estelí, Adeso Las Segovias: 2002). Un conteo rápido en una muestra aleatoria realizada por el IMC (2003) reportó 17 micro tortillerías que consumen 1,581 quintales de maíz en el año². En Managua, una sola tortillera que abastece el mercado mayoreo, procesa diariamente dos quintales de maíz, para una demanda anual de 730 quintales del grano. ¿Cuántas tortillerías existen en el país que elaboran productos todos los días del año? Suponiendo unas 2,500, con un consumo anual de 93 quintales por año - usando como modelo el caso de Estelí - , la demanda de este sector puede estimarse en 232,500 quintales al año.

Otra demanda poco estudiada ${ }^{3}$ proviene de consumidores de maíz verde (elotes y chilotes), a través de una variedad de productos: elotes, tamales, güirilas, atol, etc. Menor demanda tiene el maíz como forraje para el consumo animal, aunque pocos casos son promovidos por organizaciones vinculadas al campo que buscan un incremento en la nutrición y sanidad animal.

\section{Precios}

Históricamente, los precios fluctúan dependiendo de las temporadas de escasez y abundancia del producto en el mercado. Una revisión del precio promedio del maíz por año, en el período 
comprendido entre 1995 y $2002^{4}$ en los principales mercados nacionales del país, refleja grandes fluctuaciones entre los 8-14 dólares por quintal (ilustración 3).

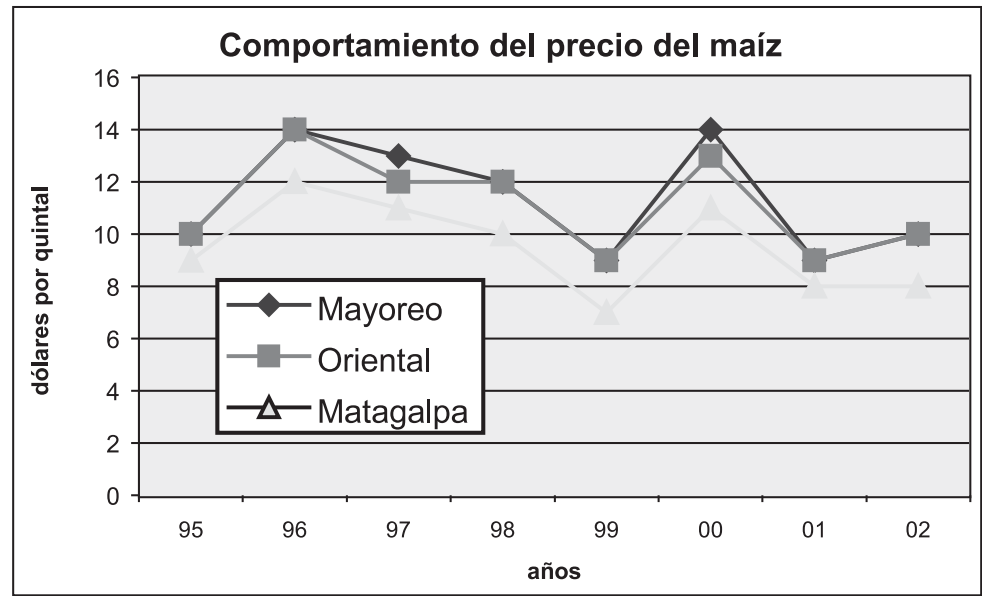

Ilustración 3. Comportamiento del precio del maíz (1995-2002)

Los mercados de granos de los departamentos muestran precios más bajos en comparación con los nacionales, que suelen estar conectados en la misma red de intermediación, donde los primeros, son abastecedores de los segundos.

Los precios en los mercados locales o departamentales, en la medida en que están más distantes de los mercados centrales, generalmente son más bajos, como se observa en la ilustración 3, que presenta una relación de precios entre el mercado Matagalpino, el Mayoreo y el Oriental de Managua.

Matagalpa es el mayor productor de maíz blanco del país y, junto a Jinotega, anualmente suma el $26 \%$ del total de maíz producido en el país.

El precio del maíz se duplica o triplica, no cuando se vende como grano entero, sino cuando es transformado en otro producto. Un ejemplo lo ilustran los siguientes cuadros donde el producto tiene tres maneras diferentes de uso.

Cuadro 3. Distribución del valor de un elote (C\$)

\begin{tabular}{|c|c|c|c|c|}
\hline Producto & Productores & $\begin{array}{c}\text { Intermediación } \\
\text { (camioneros) }\end{array}$ & Sra. Vende elotes & $\begin{array}{c}\text { Supermercado La } \\
\text { Colonia }\end{array}$ \\
\hline Maíz en elote* & 3.20 & 4.00 & 8.00 & 20.00 \\
\hline$\%$ & $16 \%$ & $20 \%$ & $40 \%$ & $100 \%$ \\
\hline
\end{tabular}

*400 elotes hacen un quintal; aproximadamente, cuatro mazorcas de maíz grande y seco hacen una libra; así, tenemos una libra de maíz seco (0.80) frente a elotes (3.20). Fuente: basado en entrevistas a directivos de UCOSD, UESA, productores y comerciantes 
En algunos supermercados como La Colonia, ubicado en Plaza España de Managua (cuadro 3), el maíz dulce San Jerónimo - cuatro elotes amarillos pequeños, empacados en pequeñas bandejas cubiertas con plástico transparente y con etiqueta - tienen un valor de 20 córdobas ${ }^{5}$ . Es decir, puede alcanzar un valor de 19 córdobas más que la libra del maíz seco que vende el productor (cuadro 4).

Cuadro 4. Distribución del valor de una libra de maíz para tortilla

\begin{tabular}{|c|c|c|c|c|c|}
\hline Producto & Productores & $\begin{array}{c}\text { Intermediación } \\
\text { (camioneros) }\end{array}$ & $\begin{array}{c}\text { Distribuidora } \\
\text { mayorista }\end{array}$ & Pulpería & Tortillería \\
\hline Maíz /tortilla** & 0.80 & 0.95 & 1.15 & 2.00 & 5.00 \\
\hline$\%$ & $16 \%$ & $19 \%$ & $23 \%$ & $40 \%$ & $100 \%$ \\
\hline $\begin{array}{l}* * \\
\text { Fue una libra de maíz salen } 10 \text { tortillas (pequeñas). C\$0.50/tortilla. }\end{array}$ \\
\hline
\end{tabular}

La semilla también alcanza un precio alto de hasta 770 córdobas el quintal, en semilla registrada de las variedades NB-9043, NB-6, NB-S y NB Nutrinta, producidas y vendidas por los centros experimentales del INTA. Otras semillas mejoradas de las variedades H-INTA991 y H-INTA-993 alcanzan un precio de 550 córdobas el quintal. Es claro que a medida que el grano tiene un atributo especial, alcanza un valor cercano a los ocho córdobas la libra en un centro de venta especializado; en contraste, la libra de maíz cultivado por los productores solamente llega a dos córdobas la libra en el mercado local o de mayoreo.

En resumen, los precios del maíz blanco seco son irregulares a lo largo del año. Alcanzan una curva máxima precios en época de verano y un descenso en época de cosecha. Es notorio cómo el mayor valor que adquiere el producto se va incorporando en las esferas de la distribución y de la transformación en nuevos productos que añaden más valor, pero los productores de granos no participan en esas actividades.

\section{La cadena de valor del grano}

El concepto de cadena describe un rango completo de actividades que son requeridas para llevar a cabo un producto desde su concepción inicial, pasando por diferentes fases de producción y procesamiento, hasta la entrega a los consumidores finales y la disposición después de su uso (Kaplinsky y Morris, 2000).

La cadena por la que se comercializa el maíz es una cadena extendida que no siempre se logra visualizar como tal, dado que el énfasis sobre el producto se pone en la finca o en la parcela de los productores (en la producción), y no en los otros eslabones. Una forma de representar esta cadena extendida del maíz lo presenta la ilustración 4 


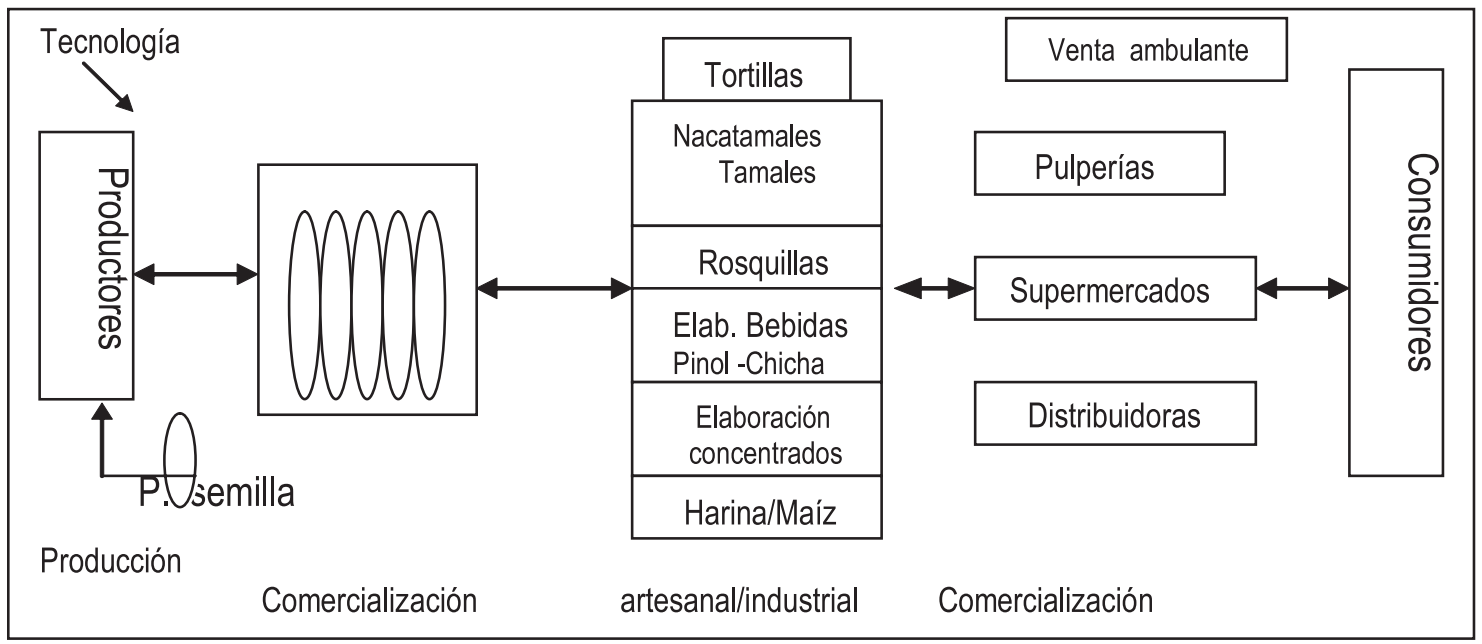

Ilustración 4. Cadena extendida del maíz

- En la producción, unos 96,000 pequeños productores se encuentran dislocados en todo el país, cultivando de manera aislada; no forman parte de redes de colaboración en información para la producción del maíz.

- Existe escasa especialización sobre granos con atributos específicos: el maíz como semilla, por ejemplo, está concentrado en el INTA y un segmento bastante pequeño de productores. La mayoría produce las mismas variedades de grano.

- La comercialización del grano se da en dos momentos claramente diferenciados: el primero, cuando es llevado desde las parcelas para ponerlo al servicio de una primera clientela nacional o extranjera, que se encarga de transformarlo; y un segundo momento, cuando se comercializa como un nuevo producto, siguiendo rutas y lógicas diferentes de distribución.

- Al igual que los productores, los comerciantes se encuentran dislocados por todo el país, pero se diferencian en que cuentan con redes de colaboración para el acopio y distribución del grano. Los comerciantes más grandes se destacan en las principales cabeceras departamentales, donde concentran mayor cantidad de producción para luego distribuirla, pero están conectados con otros comerciantes de los mercados nacionales o de Honduras y El Salvador.

- A medida que se llega al mercado nacional, el número de comerciantes se va reduciendo, de manera que la representación general del sector podría compararse con una pirámide, cuya cima es pequeña y la base, amplia.

- Cuando se compra el grano para su transformación en otro producto: cereal, rosquilla, chicha, etc., entra a una nueva fase de comercialización, como producto con valor agregado para el consumidor final. Este segundo nivel de comercialización no se aprecia como el primero, porque se dispersa en diferentes espacios geográficos. 
- El producto final, como maíz transformado, se comercializa la mayoría de las veces junto a otros productos y no solo, como ocurre en el primer nivel de comercialización. El segmento de mercado al que generalmente se destina son los pobladores de las áreas urbanas del país.

Por otra parte, el recorrido que sigue el producto desde la finca y durante el proceso de la intermediación (ilustración 5), permite observar de manera simple los nexos tre unos y otros eslabones internos en este proceso de la comercialización:

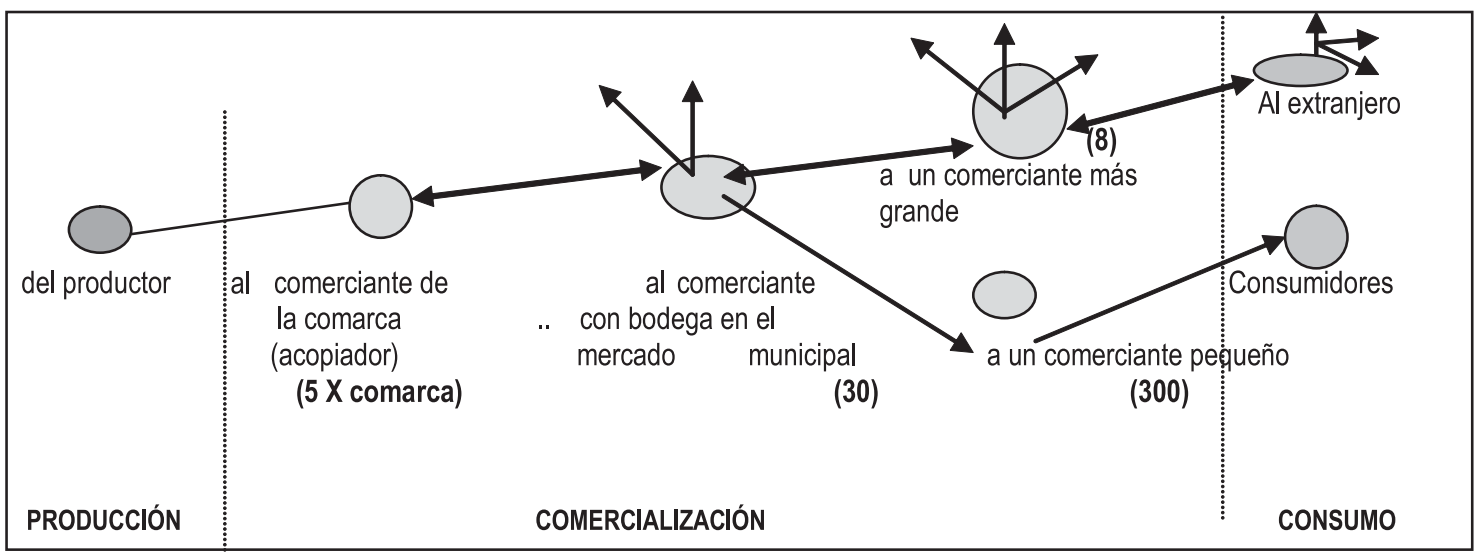

Ilustración 5. Recorrido tradicional del maíz en tiempo de cosecha.

Tomando como ejemplo a Matagalpa, los comerciantes de granos del mercado de Guanuca son una pieza clave en el eslabón de la cadena: ellos aseguran los movimientos de la cadena hacia atrás (hacia el productor) y hacia delante (hacia el consumidor). Son quienes articulan el resto de las conexiones al interior de la actividad comercial de los granos en el departamento y fuera de éste.

De cada uno de los comerciantes pueden derivarse conexiones con hasta 10 acopiadores de granos, quienes se internan en las comunidades rurales. En su conjunto, mueven el 60\% de la producción local del interior del Departamento (1,100,000 quintales aproximadamente, según datos del MAGFOR). Algunos de ellos son parte de una cadena más grande, donde el eslabón clave son los grandes comerciantes de los mercados Mayoreo y Oriental en Managua, quienes entregan dinero para el acopio y pagan por este servicio a los intermediarios ubicados en el mercado de Guanuca. Generalmente, en los primeros eslabones de la cadena, es donde se desarrollan los vínculos más cercanos entre las personas, como consecuencia de la poca disponibilidad de recursos con que cuentan para el acopio y el transporte. Muchos acopiadores trasladan la carga en transporte colectivo, otros en camionetas pequeñas.

En Jalapa ocurre lo mismo, pues la mayor parte de la producción que se destina al mercado es recolectada por pequeños comerciantes que, a su vez, tienen vínculos con comerciantes más grandes o intermediarios de granos, ubicados en las ciudades de Ocotal, Somoto y Estelí. Los intermediarios y comerciantes forman redes que les permiten acopiar y distribuir el maíz de manera permanente durante todo el año ${ }^{6}$ 


\section{Las reglas y normas en el comercio de los granos}

En el comercio de los granos existe un conjunto de normas o reglas implícitas que condicionan el accionar y el comportamiento de productores y comerciantes: se trata de la institucionalidad relacionada con el comercio (cuadro 5). El concepto de institución (North 1993, Ayala 1999) se refiere a las normas y reglas formales e informales que regulan el comportamiento de los individuos y las organizaciones de la sociedad. Las instituciones son las reglas del juego que establecen los incentivos, y las restricciones que determinan el comportamiento de las organizaciones. El proceso de comercialización, como históricamente se conoce en las zonas rurales, se va desarrollando en base de estas reglas.

Cuadro 5. Reglas identificadas en el comercio de los granos

\begin{tabular}{|c|c|c|}
\hline Regla implícita & Explicación que la sustenta & Implicaciones negativas \\
\hline $\begin{array}{l}\text { - Venta del grano: } \\
\text { se hace en la } \\
\text { casa del } \\
\text { p e q u e ñ o } \\
\text { productor }\end{array}$ & $\begin{array}{l}\text { - Dispone de un excedente, pero no tiene } \\
\text { medio de transporte ni le resulta fácil } \\
\text { contratarlo. No tiene más opción que } \\
\text { esperar a que el comerciante con vehículo } \\
\text { llegue a comprarle el grano. } \\
\text { - Salir al mercado implica tiempo, costo y } \\
\text { tomar riesgos. El pequeño productor lo ve } \\
\text { como pérdida de tiempo, "aventurar". El } \\
\text { tiende a moverse sobre lo seguro. }\end{array}$ & $\begin{array}{l}\text { - El productor no tiene } \\
\text { acceso a la información del } \\
\text { mercado, sólo a la que es } \\
\text { dada por el comerciante } \\
\text { que le visita. } \\
\text { - La visualización de lo que } \\
\text { es seguro es su barrera } \\
\text { para entrar al mercado. }\end{array}$ \\
\hline 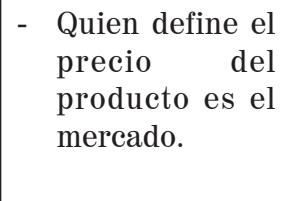 & $\begin{array}{l}\text { - Se asume que el mercado es un espacio } \\
\text { abstracto, opera de manera "mágica", no } \\
\text { tiene rostro, es una fuerza superior que rige } \\
\text { y determina las relaciones entre las } \\
\text { personas. }\end{array}$ & $\begin{array}{l}\text { - Quien produce, no puede } \\
\text { controlar ni modificar o } \\
\text { cambiar las relaciones } \\
\text { comerciales. }\end{array}$ \\
\hline $\begin{array}{l}\text { - El mercado se } \\
\text { rige por la ley de } \\
\text { la oferta y } \\
\text { demanda }\end{array}$ & $\begin{array}{l}\text { - El mercado tiene un poder que supera la } \\
\text { voluntad de las personas. Son los } \\
\text { productos existentes o ausentes los que } \\
\text { determinan el comportamiento del } \\
\text { mercado. }\end{array}$ & $\begin{array}{l}\text { - Ignora las habilidades } \\
\text { humanas para equilibrar o } \\
\text { desequilibrar la relación } \\
\text { entre oferta y demanda. }\end{array}$ \\
\hline $\begin{array}{l}\text { - } \mathrm{L} \text { a s } \\
\text { negociaciones } \\
\text { son asuntos de } \\
\text { individuos y no } \\
\text { de grupos. }\end{array}$ & $\begin{array}{l}\text { - Negociar con un grupo siempre trae } \\
\text { dificultades, dado que sus integrantes no } \\
\text { se ponen de acuerdo. }\end{array}$ & $\begin{array}{l}\text { - Refuerza el individualismo } \\
\text { y reduce importancia y } \\
\text { mérito al rol del grupo } \\
\text { organizado }\end{array}$ \\
\hline $\begin{array}{l}\text { - No hay } \\
\text { estructuras que } \\
\text { gobiernen y } \\
\text { regulen las } \\
\text { transacciones }\end{array}$ & $\begin{array}{l}\text { No hay autoridad visible competente a quien } \\
\text { recurrir, ante las injusticias o } \\
\text { desavenencias que se originan en las } \\
\text { transacciones. }\end{array}$ & $\begin{array}{l}\text { - La convicción de que no se } \\
\text { puede hacer nada, termina } \\
\text { imponiéndose } \\
\text { aceptándose. }\end{array}$ \\
\hline
\end{tabular}


Generalmente se piensa que las reglas no pueden ser cuestionadas ni cambiadas, porque no hay instancias ni espacios para hacerlo. Esto implica que el productor no puede hacer nada si está inconforme, no puede acudir a alguna autoridad para quejarse o para mejorar su posición en las negociaciones con los comerciantes. De esta manera, se interioriza que el acto de comercializar es momentáneo, efímero y, sobre todo, no está gobernado por nada ni por nadie. Es su práctica reiterada la que termina indicando que así ocurren los hechos relacionados con la comercialización y, por tanto, se terminan aceptando.

Sin embargo, ¿quién pone las reglas y de quién es la responsabilidad de cambiarlas? Las reglas se construyen en el proceso de la interacción entre productores y comerciantes, a partir de intereses, necesidades y supuestos que cada uno maneja. Al ser una construcción social, pueden ser cambiadas en el mismo proceso de interacción, cuando se observan incongruencias que se traducen en efectos negativos para unos u otros.

Basta con que algunos decidan hacer los cambios y que empiecen a funcionar. La experiencia del banco de granos de la Unión de Campesinos Organizados de San Dionisio (UCOSD) lo revela, cuando los productores organizados deciden a qué precio se pagará su maíz, con un efecto directo para que los comerciantes equiparen o mejoren los precios en la zona, si desean acopiar maíz. Ellos también modificaron la regla de la negociación como un acto individual y aislado para hacerlo de manera conjunta entre productores, apostar a que unidos pueden competir con productores medianos o grandes, o con los mismos comerciantes.

Hasta aquí, hemos visto que, aunque existe una cadena compleja por la cual circula el maíz, o sobre la cual se van derivando otra serie de cadenas en dependencia del destino final del producto, los productores no sólo están en el primer eslabón, sino que están desconectados del resto de los eslabones. Sus empresas repiten el mismo esquema de desconexión que tiene el productor individual, como se verá en la siguiente sección.

\section{Modelos de retención de granos}

Conceptualmente, por modelo se entiende "un prototipo de actuación en el que objetivos, contenidos, métodos y procedimientos o estrategias se encuentran relacionados e interconectados en un todo significativo" (Karlheinz y Hege: 1997). Los modelos son resultado de circunstancias y condiciones históricas que influyen paulatinamente en los fenómenos sociales.

\subsection{Conceptos y supuestos}

El modelo promovido por la Unidad Estratégica de Seguridad Alimentaria (UESA) en la experiencia de la Empresa Comercializadora de Granos (ECOGRANOS) de San Ramón y la Empresa de Granos de Jalapa (EGRANOJAL), concibe la retención como un servicio general al productor donde éste, individualmente, siempre es el dueño del producto con opción de venderlo por su propia cuenta o a través de la empresa. Por otro lado, el Banco de Granos de la Unión de Campesinos Organizados de San Dionisio (UCOSD) lo asume como una actividad centralizada por el banco. El objetivo no es generar utilidades para la empresa, sino trasladar la mayor parte del precio final del grano a los productores. 
El modelo UESA revela la visión gubernamental de "impulsar empresas de comercialización manejadas por pequeños productores, a partir de amplios programas de capacitación a líderes y dirigentes, facilitando infraestructura de almacenamiento y rehabilitación de las instalaciones dejadas por ENABAS, facilitando capital de arranque para que las empresas puedan pagar a sus socios-productores al momento de entregar el producto" (MAG-FOR 2002).

El supuesto clave aquí, es que la capacitación ${ }^{7}$ la infraestructura y un capital de arranque van a permitir a los productores mejorar su situación en el mercado, competir y mejorar sus ingresos vía precios. La creación de relaciones con otros actores de la cadena de comercialización, el acceso a la información y al conocimiento sobre cómo opera el mercado, sus lógicas, etc., queda ausente y ésta es una de las grandes debilidades del modelo, porque todo su esfuerzo se orienta hacia lo interno, y no hacia la construcción de la relación con el mercado.

Otro supuesto es que la capacidad de acumular capital propio viene dado por la venta de acciones: cuantas más acciones se vendan, mejor y cuantos más productores se involucren, el resultado será más exitoso. El número parece determinante para justificar la alta inversión que empresas de esta naturaleza demandan, aunque al final se pierde legitimidad en la medida en que la propia organización no logra cohesionar a los productores como un bloque compacto para incidir en la reorganización del mercado de los granos en las localidades más inmediatas.

Por su parte, el modelo del banco de granos de la UCOSD se concibe como una empresa asociativa de los productores, manejada por ellos mismos, bajo el supuesto que la relación productor-comerciante es siempre lesiva para el productor y donde los intereses y necesidades de ambos son opuestos. Se asume que el comerciante siempre busca ventajas sobre el productor, por lo que retener la cosecha en manos de los productores, no solo evita que el grano sea acopiado por comerciantes a precios bajos, sino que les resta fuerza y les obliga a desaparecer o modificar ciertas normas en su relación con otros productores no asociados.

El propósito es cambiar las relaciones de poder dominante de los comerciantes respecto a los productores, disminuir el poder de los unos y aumentar el de los otros. El supuesto es que este objetivo se logra sólo mediante el acopio y venta de la producción al por mayor y de manera conjunta. De alguna manera, trabajan para cambiar las reglas del juego interiorizadas, pero estas reglas no son del todo claras, y la estrategia se limita a la concentración del grano en la bodega, para luego vender como un solo productor con mayor capacidad de negociación.

Ambos modelos buscan cubrir los costos operativos en que incurren cada año para asegurar el funcionamiento de las empresas, pero dependen de recursos externos para su capital de trabajo. El modelo UESA busca ingresos por la venta del servicio de almacenamiento, comisión de entre el 1.5 y el 3\% sobre la venta del maíz, más intereses por el uso de dinero dado en crédito a los productores durante el período en que necesitan almacenar sus granos; prevén redistribuir utilidades cuando se obtengan; pese a tener buenas entradas por los servicios 
prestados durante la temporada, no se alcanza la rentabilidad. El Banco de Granos de la UCOSD, aunque cubre sus costos operativos, utiliza los intereses por uso de crédito (dinero dado en adelanto mientras se vende) para cubrir obligaciones financieras que tienen que pagar; y hace uso de un porcentaje de los reajustes por quintal que le corresponde a cada socio después de vender el maíz, según sus propios acuerdos (cuadro 7).

Cuadro 6. Elementos que configuran los modelos de retención de granos

\begin{tabular}{|c|c|c|c|}
\hline CRITERIO & UCOSD & UCOGRANOS & EGRANOJAL \\
\hline Objetivos & $\begin{array}{l}\text { - Trasladar a los productores asociados } \\
\text { un porcentaje mayor del valor total que } \\
\text { adquiere el maíz, cuando ingresa a los } \\
\text { canales de distribución, por la vía de } \\
\text { mejores precios. }\end{array}$ & \multicolumn{2}{|c|}{$\begin{array}{l}\text { - Mejorar la posición negociadora del } \\
\text { agricultor en el proceso comercial al } \\
\text { decidir el momento de la venta de su } \\
\text { producto. Hace participar al agricultor } \\
\text { en el valor añadido al grano por el } \\
\text { procesamiento y almacenamiento. }\end{array}$} \\
\hline $\begin{array}{l}\text { Reglas del } \\
\text { juego } \\
\text { (internas) }\end{array}$ & $\begin{array}{l}\text { - Los socios venden su maíz al banco de } \\
\text { granos bajo un régimen de cuotas. } \\
\text { - Los socios participan en la fijación del } \\
\text { precio de compra y de venta del maíz } \\
\text { mediante el mecanismo de consulta. }\end{array}$ & \multicolumn{2}{|c|}{$\begin{array}{l}\text { - El socio es el único responsable por } \\
\text { sus decisiones, por su éxito o su } \\
\text { fracaso. } \\
\text { - El socio tiene la opción de hacer } \\
\text { arreglos de venta de su maíz con quien } \\
\text { quiera cuando lo considere } \\
\text { conveniente o autoriza a la empresa } \\
\text { para que lo venda. } \\
\text { - La empresa es sólo un mecanismo de } \\
\text { apoyo para el productor individual. } \\
\text { - Las negociaciones comerciales son } \\
\text { ágiles y rápidas ya que no se debe } \\
\text { consultar con ningún grupo. De este } \\
\text { modo, el productor ahorra tiempo. }\end{array}$} \\
\hline $\begin{array}{l}\text { Vínculos con } \\
\text { el mercado }\end{array}$ & $\begin{array}{l}\text { - Solo en temporada de venta del maíz a } \\
\text { través del monitoreo de precios. } \\
\text { - La venta generalmente se hace a uno o } \\
\text { dos intermediarios de Matagalpa o de } \\
\text { otros mercados, incluyendo } \\
\text { hondureños y salvadoreños. }\end{array}$ & \multicolumn{2}{|c|}{$\begin{array}{l}\text { - Como individuo, es buscado por } \\
\text { comerciantes o a la inversa, pero se } \\
\text { hace sólo en el momento en que se } \\
\text { necesita vender; luego se pierde el } \\
\text { vínculo. }\end{array}$} \\
\hline
\end{tabular}

Fuente: elaboración propia 
Cuadro 7. Aspectos comunes y diferentes en cada caso

\begin{tabular}{|c|c|c|c|}
\hline Criterios /casos & UCOSD & ECOGRANOS & EGRANOJAL \\
\hline Años de operar & 11 años & 6 años & 4 años \\
\hline Socios. & 216 & $\begin{array}{l}\qquad 400 \\
22 \text { accionistas activos en } \\
\text { promedio. }\end{array}$ & $\begin{array}{l}\qquad 300 \\
25 \text { accionistas activos en } \\
\text { promedio. }\end{array}$ \\
\hline $\begin{array}{l}\text { Mecanismo de } \\
\text { participación. }\end{array}$ & $\begin{array}{l}\text { - Acciones. } \\
\text { - } 20 \text { dólares la acción. } \\
\text { - Un límite de } 20 \\
\text { acciones por socio. }\end{array}$ & $\begin{array}{l}\text { - Acciones. } \\
\text { - } 10 \text { dólares la acción. } \\
\text { - } \quad \text { Límite de una a tres } \\
\text { acciones por socio. }\end{array}$ & $\begin{array}{l}\text { - } \text { Acciones. } \\
\text { - } 10 \text { dólares la acción. } \\
\text { - Límite de una a tres } \\
\text { acciones por socio. }\end{array}$ \\
\hline $\begin{array}{ll}\text { Fuente } & \text { /ароуо } \\
\text { financiero. } & \end{array}$ & $\begin{array}{l}\text { - Fondo revolvente } \\
\text { apoyado por Agencias } \\
\text { de Cooperación } \\
\text { administrado por } \\
\text { DDnnEscs. }\end{array}$ & $\begin{array}{l}\text { - Fondo de crédito de } \\
\text { la UESA } \\
\text { administrado por la } \\
\text { UCA San Ramón. }\end{array}$ & $\begin{array}{l}\text { - Fondo de crédito de } \\
\text { la UESA } \\
\text { administrado por } \\
\text { Bancentro. }\end{array}$ \\
\hline Monto / inversión & & 210,000 US $\$$ & 300,000 US $\$$ \\
\hline Capital de trabajo & $\begin{array}{l}\text { - Hasta } 83,000 \text { dólares } \\
\text { anuales vía crédito } \\
\text { administrado por } \\
\text { PRODESSA con una } \\
\text { tasa de interés del } 5 \% \text {. }\end{array}$ & $\begin{array}{l}\text { - Hasta } 80,000 \text { dólares } \\
\text { vía crédito de la } \\
\text { UESA administrado } \\
\text { por la UCA San } \\
\text { Ramón con t/interés } \\
\text { del } 6 \% \text {. }\end{array}$ & $\begin{array}{l}\text { - } 150,000 \text { dólares } \\
\text { anuales vía crédito } \\
\text { de BANCENTRO- } \\
\text { fideicomiso, con } \\
\text { tasa de interés del } \\
6 \% .\end{array}$ \\
\hline $\begin{array}{l}\text { Propiedad de la } \\
\text { infraestructura de } \\
\text { almacenamiento }\end{array}$ & $\begin{array}{l}\text { - Propia aunque aún } \\
\text { tienen pendiente un } \\
\text { crédito por } \\
\text { construcción y } \\
\text { mejoras en las } \\
\text { bodegas. }\end{array}$ & $\begin{array}{l}\text { - De ENABAS tienen } \\
\text { contrato de arriendo } \\
\text { por } 10 \text { años con } \\
\text { opción a compra por } \\
27,500 \text { dólares. } \\
\text { - Pagan } 300 \text { dólares } \\
\text { mensuales de } \\
\text { alquiler. }\end{array}$ & $\begin{array}{l}\text { - De la UCA “Santos } \\
\text { Reyes" a la que se le } \\
\text { adeuda un monto } \\
\text { de } 45,000 \text { dólares } \\
\text { por infraestructura } \\
\text { y terreno existente. }\end{array}$ \\
\hline
\end{tabular}

Las similitudes de los modelos se deben a que no operan con capital propio, sino con recursos de crédito que son administrados por instancias diferentes a cada empresa, mecanismo que permite regular y controlar su funcionamiento desde una instancia externa, aunque con roles diferentes, como se verá más adelante.

Las tres empresas manejan las acciones como mecanismo para que los productores participen como co-propietarios en la iniciativa de comercialización, sobre el supuesto de que al comprometer su dinero, los productores estarán desarrollando compromisos más fuertes con la empresa y, por tanto, la organización tendrá mayor estabilidad. También se parecen en que las tres concentran el producto en un solo espacio para controlar la calidad y las transacciones mismas. De este modo, se pretende vender una imagen de empresas sólidas, con suficiente capital y respaldadas por organizaciones y agencias de cooperación. Nacieron 
o en el camino van queriendo ser gigantes; detrás, parece estar la idea de que sólo con empresas grandes se puede competir con los canales convencionales del mercado de los granos.

Finalmente, todas se auto llaman empresas, pero la figura de empresa es aún un proceso en construcción - en su primera etapa-, en el que se mezclan más roles e intereses gremiales que funciones propiamente gerenciales, necesarios para enfrentar la competitividad de quienes ya están en el mercado. Los esfuerzos se concentran más en el acopio y almacenamiento de los granos, que en crear su propio mercado.

Las diferencias entre los modelos se observan en el tipo de persona jurídica adquirido. Mientras el modelo del banco de granos de la UCOSD es una asociación de campesinos manejada por ellos mismos, las otras son sociedades anónimas que contratan personal administrativo fuera de la organización. La primera juega un rol más gremial. Es parte de una organización mayor que busca paulatinamente la satisfacción de otras necesidades complementarias a sus asociados, abriendo espacios para ello ${ }^{8}$ Las otras dos empresas no cuentan con esta motivación.

Otras diferencias se encuentran en la forma de organización interna y de operar para asegurar el acopio y almacenamiento de los granos. El modelo de la UCOSD responde a un proceso de organización en el que hay participación de los asociados en la definición de cantidad a acopiar, precio base de compra por parte del banco y en el establecimiento de las reglas del juego para cada ciclo de producción. En el modelo UESA, dado que se basa en la venta de servicios, la participación de los socios accionistas tiende a ser menor y los servicios son mayormente usados por otros productores particulares de mayor tamaño, lo que ha generado conflicto inclusive con socios accionistas ${ }^{9}$. La diferencia entre ser socio accionista 0 , simplemente, cliente, no es clara.

\subsection{Vínculos entre eslabones}

En la perspectiva de la cadena, el grado de fortaleza entre los eslabones asegura mayores ventajas para competir, porque el esfuerzo de todos resulta en beneficios mutuos. Sin embargo, en los tres casos estudiados, el vínculo entre la producción y la comercialización sigue siendo débil. Los mayores esfuerzos se han concentrado en la producción, el acopio y almacenamiento del grano.

Al graficar una línea del tiempo entre los eslabones de la cadena, se observa una desproporción entre la fase de la producción, el procesamiento y la comercialización del grano. El tiempo requerido por cada actividad restringe al productor hacer todo con el mismo nivel de efectividad (ilustración 6). El tiempo influye mucho en el desarrollo de capacidades y habilidades de una persona y éstas derivan en la experiencia. 


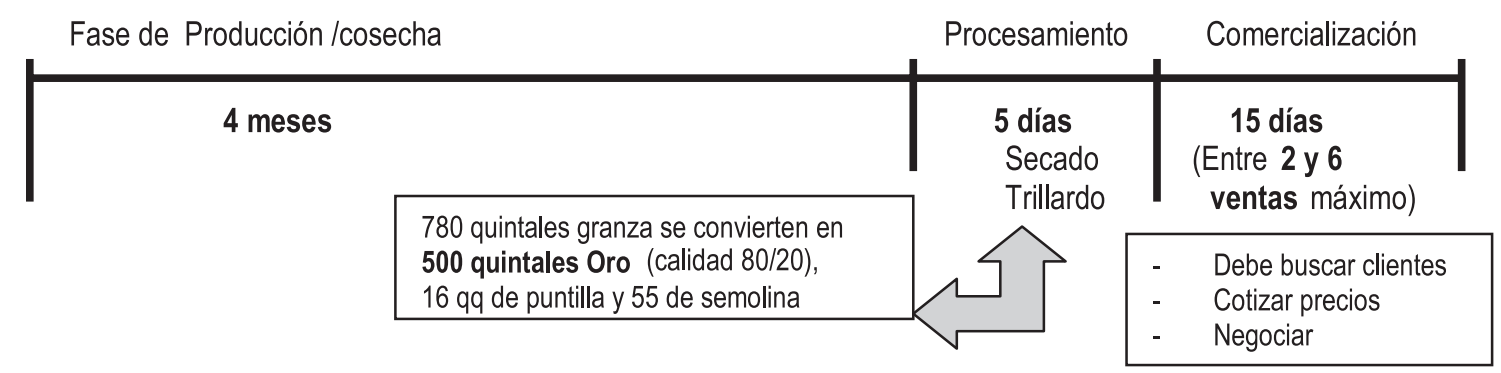

Ilustración 6. Línea del tiempo entre fases de la cadena de arroz (EGRANOJAL)

La comercialización es tan importante como la producción y obliga a cierto grado de especialización. No obstante, los productores accionistas de EGRANOJAL (ilustración 6), en este caso, pasan la mayor parte del tiempo del año en la fase de la producción y muy poco en la de comercialización, al igual que el banco de granos de la UCOSD (ilustración 7), donde ya no intervienen individualmente los socios porque han confiado esta actividad a su empresa.

\begin{tabular}{|c|c|c|}
\hline Producción/Cosecha & almacenamiento & Venta \\
\hline 7 meses & 8 meses & 1 a 4 ocasiones
\end{tabular}

Ilustración 7. Línea del tiempo entre fases de la cadena del maíz (UCOSD)

Efectivamente, en las tres o cuatro ocasiones en que se establecen relaciones con los intermediarios, es difícil que la empresa pueda conquistar un segmento de mercado importante. A finales de 2002, el banco de granos de la UCOSD incrementó sus ventas a 20, porque se está gestando un cambio de visión a lo interno: ya no se pretende vender como gran mayorista un solo lote, sino vender el grano en cantidades más pequeñas y ponderar el precio promedio de todas las transacciones. Este cambio ha sido influenciado por la dificultad de encontrar un solo comprador para adquirir todo el grano en una sola transacción, y responder a la presión de los socios cuando no logran vender el grano al mejor precio de la plaza.

\subsection{Roles, interacción y perspectivas de los actores del modelo}

Los modelos de retención de granos son un actor social en el sentido propuesto por Long, quien argumenta que "los actores sociales son "sabedores y capaces". Ellos intentan resolver los problemas, aprenden cómo intervenir en el flujo de acontecimientos sociales de su entorno y monitorean continuamente sus propias acciones, observando cómo otros reaccionan frente a su comportamiento y toman nota de circunstancias varias y contingentes" (citado por Mendoza 2002). 
Los actores sociales deciden y actúan en correspondencia, aunque la decisión no es un acto individual y aislado. Forma parte de la interacción y de la conjunción de valores e intereses de unos y otros. En este sentido, las decisiones pueden verse como parte de un proceso donde interviene más el tipo de relación y de intereses que la noción del individuo, afirma Long. Desde esta perspectiva, el actor social en los modelos de retención de granos es la interacción entre la empresa, sus asociados y las organizaciones que la apoyan externamente en su configuración y funcionamiento, dado que ninguno de ellos puede decidir al margen de los otros.

El actor social es la red de relaciones sociales establecidas entre las instancias que intervienen de una u otra manera en los modelos de retención de granos. Es en esta red donde se van desarrollando habilidades para influenciarse unos a otros, llegar a acuerdos, hacer circular la información, los recursos y dar curso al proceso. Sin esta red, difícilmente funcionarían las empresas. Cada agente es complementario a los otros para hacer posible la retención y la comercialización. Dependiendo del nivel de eficiencia con que actúe un agente, así se verá el nivel de eficiencia del actor en su conjunto. Veamos a continuación cómo se dan las relaciones entre los diferentes agentes en los casos estudiados. Las siguientes gráficas muestran este tipo de relaciones, mientras los recuadros abordan las funciones.

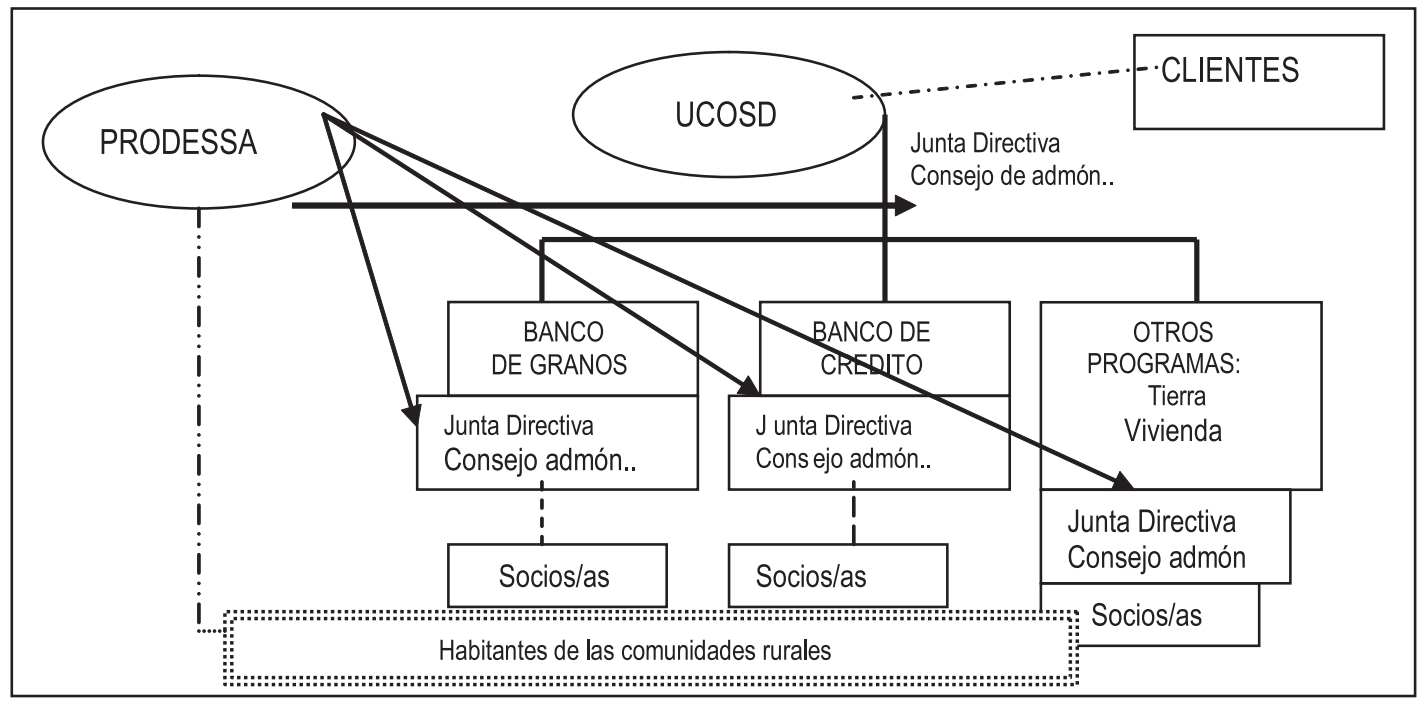

Ilustración 8. Relación entre agentes en el banco de granos (UCOSD).

El modelo de retención de granos de la UCOSD tiene cuatro agentes involucrados: los sociosfamilias campesinas (13 comunidades), la organización campesina, el programa de comercialización de granos y la ONG que la acompaña (ilustración 8 y cuadro 8). Los socios en sus comunidades son una contraparte local desde adentro, mientras la ONG es una contraparte externa. La organización campesina (UCOSD) es la gestora del programa, y la directiva del banco dirige el proceso. Todos estos agentes conforman un tipo de actor social que hace posible el acopio y la venta del grano. 
Cuadro 8. Funciones, compromisos y beneficios entre agentes (UCOSD)

\begin{tabular}{|c|c|c|c|c|}
\hline Criterios & Socios-Familias & $\begin{array}{c}\text { Banco de Granos } \\
\text { Asociados }\end{array}$ & UCOSD & Prodessa \\
\hline Funciones & $\begin{array}{l}\text { - Plantear sus } \\
\text { problemas para } \\
\text { buscar salidas. } \\
\text { - Participar en las } \\
\text { reuniones de } \\
\text { productores por } \\
\text { comunidad para } \\
\text { e l a b o r a r } \\
\text { propuestas. } \\
\text { - Vender su maíz a } \\
\text { través del banco. } \\
\text { - Informarse y } \\
\text { cuidar la } \\
\text { propiedad social. }\end{array}$ & 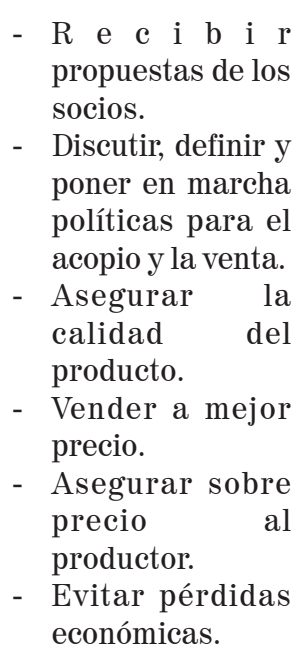 & $\begin{array}{l}\text { - A r t i c u l a } \\
\text { demandas de } \\
\text { la gente } \\
\text { (reflexión). } \\
\text { - D i s e ñ a } \\
\text { programa de } \\
\text { desarrollo. } \\
\text { - G e s t i o n a } \\
\text { fondos ante } \\
\text { Prodessa. } \\
\text { - Representa } \\
\text { legalmente a } \\
\text { l o s } \\
\text { programas. }\end{array}$ & $\begin{array}{l}\text { - Investigación } \\
\text { (incluye control y } \\
\text { auditoria). } \\
\text { - M o n i t o r e o } \\
\text { esporádico sobre } \\
\text { efectos del banco } \\
\text { en la vida de la } \\
\text { comunidad con } \\
\text { habitantes de las } \\
\text { comunidades no } \\
\text { socios. } \\
\text { - Asesoría, fomentoy } \\
\text { reflexión sobre } \\
\text { resultados del } \\
\text { banco. } \\
\text { - Intermediación de } \\
\text { financiamiento. }\end{array}$ \\
\hline
\end{tabular}

Las relaciones hacia el lado interno (el banco, los socios, la organización) son menos sólidas que las existentes hacia el lado externo entre el banco y Prodessa. No obstante, unos y otros van condicionando su propio comportamiento en relación a los otros y, en su conjunto, mantienen la armonía del esquema de funcionamiento por la interdependencia. PRODESSA funciona como ente regulador y facilitador entre la organización (dirigencia) y las comunidades donde residen los socios. Con los habitantes, monitorea el avance y los problemas de la organización para presionar e inducir cambios en la directiva. La comunidad sirve como termómetro a PRODESSA para saber qué está pasando e incidir en las instancias directivas de la UCOSD.

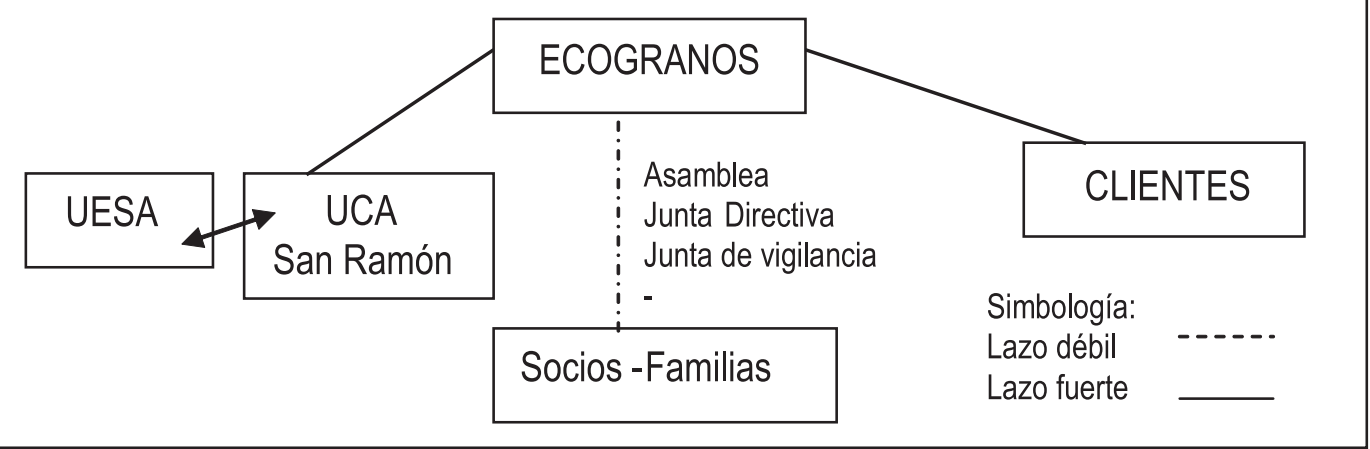

Ilustración 9. Relación entre agentes en la experiencia de ECOGRANOS 
Cuadro 9. Funciones, compromisos y beneficios entre agentes (ECOGRANOS

\begin{tabular}{|c|c|c|c|c|}
\hline & Socios-Familias & EMPRESA & UCA San Ramón & UESA \\
\hline Funciones & 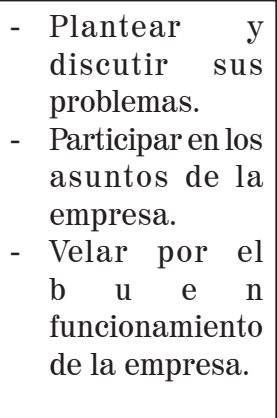 & $\begin{array}{l}\text { - Vender el servicio } \\
\text { de retención de } \\
\text { granos. } \\
\text { - Apoyar al productor } \\
\text { con información } \\
\text { sobre precios y } \\
\text { momento de venta. } \\
\text { - Capitalizarse y } \\
\text { distribuir utilidades } \\
\text { entre sus socios. }\end{array}$ & $\begin{array}{l}\text { - } \text { Ejecutar proyectos de } \\
\text { apoyo a los } \\
\text { p r o d u c t o r e s } \\
\text { asociados a las } \\
\text { cooperativas. } \\
\text { - Administrar el fondo } \\
\text { de crédito para } \\
\text { retención. } \\
\text { - Colaborar en el } \\
\text { funcionamiento de la } \\
\text { empresa. }\end{array}$ & $\begin{array}{l}\text { - A p y a r } \\
\text { proyectos de } \\
\text { desarrollo para } \\
\text { los pequeños } \\
\text { productores. } \\
\text { - Actualmente no } \\
\text { tiene relación } \\
\text { directa con } \\
\text { ECOGRANOS. }\end{array}$ \\
\hline
\end{tabular}

La UCA juega un rol clave para el sostenimiento del modelo: administra los recursos y se apoya en su propio tejido institucional para relacionarse con las cooperativas y mantener viva la imagen de ECOGRANOS ante los productores, porque se dedica exclusivamente en la venta del servicio (ilustración 9 y cuadro 9). La delimitación clara de funciones permite a la empresa no diluirse en tareas que no se relacionan la obtención de ingresos por la venta del servicio. Esta empresa ha logrado tejer vínculos con instituciones y organizaciones que atienden a productores para conquistarlas como clientes fijos y más seguros, en vez de esperar a productores individuales.

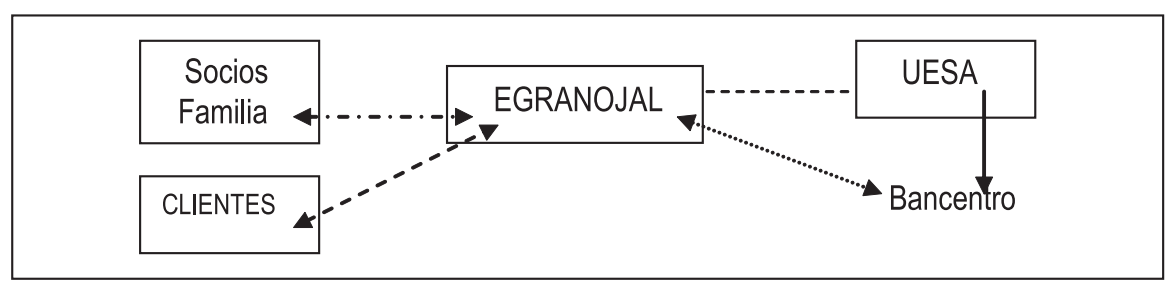

Ilustración 10. Relación entre agentes en la experiencia de EGRANOJAL

EGRANOJAL es el caso donde hay menos agentes y vínculos. La relación entre socios y empresa es débil, tanto como la relación de la empresa con el mercado (ilustración 10 y cuadro 10).

Cuadro 10. Funciones, compromisos y beneficios entre agentes (EGRANOJAL)

\begin{tabular}{|c|c|c|c|}
\hline & Socios-Familias & EMPRESA & UESA \\
\hline Funciones & $\begin{array}{l}\text { - La mayoría ya no se } \\
\text { sienten parte de la } \\
\text { i n i c i a t i v a } \\
\text { argumentando que no } \\
\text { reciben beneficios. }\end{array}$ & $\begin{array}{l}\text { - Vender el servicio de } \\
\text { retención de granos. } \\
\text { - Apoyar la } \\
\text { comercialización de los } \\
\text { pequeños productores } \\
\text { informándoles del precio } \\
\text { y vendiendo por ellos } \\
\text { cuando estos lo soliciten. }\end{array}$ & $\begin{array}{l}\text { - Apoyar proyectos de } \\
\text { desarrollo para los } \\
\text { pequeños productores. } \\
\text { - Actualmente, la relación } \\
\text { con EGRANOJAL es de } \\
\text { seguimiento a controles } \\
\text { administrativos sobre el } \\
\text { crédito que reciben para } \\
\text { apovar la retención. }\end{array}$ \\
\hline
\end{tabular}


EGRANOJAL no cuenta con un agente externo que juegue el rol de administración de recursos para crédito y de desarrollo a la parte gremial. Tiene fuentes de apoyo financiero, pero no cuenta con aliados claves que, de manera estable, le ayuden a fortalecerse internamente.

En todos los casos, las relaciones con el mercado son débiles. ¿Por qué? Primero, se asume que la tarea más grande consiste en montar y hacer funcionar la empresa y aquí se concentran la mayor parte de los esfuerzos, pero no se puede pensar en una empresa sin trabajar en asegurar el mercado. Segundo, existe la idea de que el mercado va a aparecer, sin entender que este espacio requiere trabajo, ya sea para construirlo, reorganizarlo o conquistarlo. Tercero, los lazos débiles con el mercado son una expresión de que se trabaja parcialmente; sus problemas de comercialización se deben a la falta de alianzas con compradores; y no se reconocen oportunidades para mejorar en los comerciantes u otro tipo de productoresprocesadores.

\subsection{Oportunidades para los modelos}

Las oportunidades son hechos creados fundamentalmente por otros. Son situaciones que surgen como resultado de fenómenos y procesos desarrollados por una diversidad de actores. Es el potencial de uso lo que hace que una situación se constituya en una oportunidad (Mendoca, 2001). Bajo este concepto, las oportunidades de las empresas están fuera de ellas mismas, pero no las buscan porque, al estar encerradas en sí mismas, no logran ver lo que hay más allá de lo que siempre han hecho y siguen haciendo,.

Algunas oportunidades identificadas en el transcurso del estudio para la producción y comercialización de maíz se resumen en el cuadro 11.

Cuadro 11. Oportunidades para comercializar con el maíz

\begin{tabular}{|c|c|c|}
\hline $\begin{array}{l}\text { Productos con } \\
\text { demanda }\end{array}$ & $\begin{array}{l}\text { Contenido de la oportunidad } \\
\text { (Situación, condiciones, etc.) }\end{array}$ & $\begin{array}{c}\text { ¿Qué hacer para aprovechar las } \\
\text { oportunidades? }\end{array}$ \\
\hline $\begin{array}{l}\text { Tortillas. } \\
\text { E la b o r a c ión } \\
\text { artesanal o semi } \\
\text { industrial. }\end{array}$ & $\begin{array}{l}\text { - Hábito y tradición de consumo popular. } \\
\text { - Procesamiento fácil de hacer y dislocado } \\
\text { en todo el país. } \\
\text { - } \\
\text { - } \text { La calidad se mide en el color de la tortilla } \\
\text { (blanca es muy buscada) de apariencia } \\
\text { suave y fresca. } \\
\text { - La tortilla empacada ha llegado a } \\
\text { supermercados y pulperías, pero hay } \\
\text { preferencia por la tortilla hecha a mano y } \\
\text { del día. }\end{array}$ & \multirow{3}{*}{$\begin{array}{l}\text { - Las empresas retenedoras } \\
\text { necesitan información del segmento } \\
\text { del mercado específico y priorizar } \\
\text { las que más demandan maíz. Los } \\
\text { estudios pueden ser solicitados a } \\
\text { instancias especializadas, no tiene } \\
\text { que hacerlos la empresa). } \\
\text { - Las empresas necesitan salir de las } \\
\text { bodegas para crear la relación } \\
\text { estable con el mercado y captar las } \\
\text { señales de éste para orientar el } \\
\text { proceso productivo de sus } \\
\text { asociados. Necesitan invertir la } \\
\text { dinámica que han seguido hasta } \\
\text { ahora: producir para luego ver a } \\
\text { quien vender, en vez de saber quien } \\
\text { compra y cómo, para luego } \\
\text { producirlo. }\end{array}$} \\
\hline $\begin{array}{l}\text { Harina de maíz } \\
\text { ( c o n s u m o } \\
\text { humano y } \\
\text { animal). }\end{array}$ & $\begin{array}{l}\text { - Incremento de la demanda, dado que } \\
\text { ahorra tiempo para la elaboración de } \\
\text { productos como tortillas y otros productos. }\end{array}$ & \\
\hline $\begin{array}{l}\text { Rosquillas, } \\
\text { rosquetes, pan } \\
\text { dulce. }\end{array}$ & $\begin{array}{l}\text { - Hábito y tradición de consumo popular, } \\
\text { inclusive siguiendo el mercado étnico en } \\
\text { el extranjero. }\end{array}$ & \\
\hline
\end{tabular}




\begin{tabular}{|c|c|c|}
\hline $\begin{array}{l}\text { Cereales mixtos } \\
\text { Pinolillo. }\end{array}$ & \multirow{3}{*}{$\begin{array}{l}\text { - Saber hacer en pequeño que se puede } \\
\text { multiplicar avanzando a marcas y } \\
\text { empaques variados. } \\
\text { - Mujeres que ganan dinero con la } \\
\text { elaboración y venta de estos productos. } \\
\text { - Lugares micro localizados donde } \\
\text { sobresale un tipo de producto: rosquillas } \\
\text { (Somoto, Rivas, Darío) Chicha (Masaya) } \\
\text { etc. }\end{array}$} & \multirow{5}{*}{$\begin{array}{l}\text { - Asumiendo la comercialización coo } \\
\text { una actividad regular y no } \\
\text { esporádica. } \\
\text { - Experimentando con ciertos } \\
\text { productos para el mercado. } \\
\text { - Como proveedores de algunas } \\
\text { tortillerías, rosquilleras, fabricantes } \\
\text { de cereales, etc. Atendiendo a sus } \\
\text { criterios de calidad, plazos para } \\
\text { entrega, etc. } \\
\text { - Establecer alianzas y redes de } \\
\text { distribución. }\end{array}$} \\
\hline $\begin{array}{l}\text { Bebidas } \\
\text { Chicha rosada } \\
\text { Pozol. }\end{array}$ & & \\
\hline $\begin{array}{l}\text { Elotes }^{10} \text { tamales } \\
\text { y guirilas. }\end{array}$ & & \\
\hline $\begin{array}{l}\text { Elotes y } \\
\text { Chilotes en } \\
\text { supermercados. }\end{array}$ & $\begin{array}{l}\text { - } \text { Tienen mejor precio. } \\
\text { - El grano es de color amarillo. } \\
\text { - } \quad \text { Son pocos los que producen este grano. } \\
\text { - El producto se está importando desde } \\
\text { Costa Rica. }\end{array}$ & \\
\hline $\begin{array}{lr}\text { Forraje para el } \\
\text { ganado en } \\
\text { época } & \text { de } \\
\text { verano. } & \end{array}$ & $\begin{array}{l}\text { - Hay demanda de alimento para el } \\
\text { ganado. } \\
\text { - Nadie está trabajando con el maíz como } \\
\text { forraje. }\end{array}$ & \\
\hline
\end{tabular}

- $\quad$ El conocido maizón y el maíz desgranado a mano tienen precios superiores al resto de maíz híbrido o mejorado, y al desgranado en maquinas (caso Jalapa). Las razones son: i) grano grande más rendidor, blanco, sin ojo negro, ii) grano sano, seco, seleccionado y limpio, iii) se paga entre 20 y 30 córdobas más por quintal de maíz en estas condiciones.

- Los comerciantes aseguran estar dispuestos a pagar mejor precio por el maizón o por el maíz presentado limpio y sano, un grano de excelente calidad para el mercado. Para este maíz criollo y limpio, existen segmentos de mercado con demanda regular. Es preferido tanto por las tortilleras, como por gente de las áreas rurales afectadas por la sequía que se ven obligadas a comprar semilla. No obstante, es una variedad de grano que ha dejado de ser cultivada por los productores, debido a la oferta y recomendaciones técnicas sobre el uso de semillas mejoradas, que responde más a una visión productivista de las instituciones de apoyo al campo, a quienes les preocupa incrementar los rendimientos productivos, al margen de la demanda del producto en el mercado.

Las rosquilleras de Somoto prefieren el maíz chinandegano frente al resto de maíz de Jalapa o de San Dionisio, por la característica de que ese grano es más cristalino, no lleva "ojo negro" y les permite elaborar una rosquilla con mejor calidad y presentación.

- Existen otros compradores de maíz: i) granjas avícolas; ii) ingenios; iii) industria de harina de maíz (maseca); y iv) industria de cereales, aceites, snack food, industria de enlatados (maíz dulce en grano) entre otros. Si se conocen los requerimientos de estas empresas, el tipo de exigencias que establecen y se valora la capacidad de los productores para satisfacer una sus demandas, hay una oportunidad de mercado. Pero se necesita crear una imagen de credibilidad y responsabilidad por parte de los productores para cumplir con las entregas, plazos y calidades. 
- La ausencia de pequeña industria local procesadora de alimentos (cereal y harina de maíz), para consumo humano y animal (concentrado incluyendo rastrojos), son oportunidades para explorar la transformación del grano en el ámbito local, en búsqueda de agregar valor.

- Otras oportunidades se desprenden de conocimientos a lo interno de las organizaciones, donde algunos socios, además de ser productores, comercializan granos individualmente. Lejos del conflicto en el que se han visto involucrados por el choque de visiones (caso UCOSD), este hecho representa una oportunidad para alimentarse del saber y de las relaciones establecidas por estos socios con el mercado. Ellos podrían ser el medio a través del cual la empresa crea su propia red de distribución.

Mientras estas oportunidades están esperando, los productores están enfrascados en cultivar un maíz que no se sabe quién lo comprará, ni para qué lo usarán, lamentándose porque sus costos de producción son altos y que los precios de su producto son bajos. Vemos a sus empresas más preocupadas por el cuido del grano en la bodega, que por la opinión de quienes compran el grano y la calidad del producto en el que transforman el maíz.

Las empresas de los productores actúan con la misma lógica que el productor tradicional: se deshacen de una sola vez de la producción, con ventas al por mayor y sin agregar valor, sin darse cuenta de que al vender al por mayor, salen automáticamente del mercado, puesto que ya no tienen producto que vender. De este modo, es difícil construir una relación comercial estable. Uno de los secretos para permanecer en el mercado consiste en tener siempre algún producto que ofrecer.

Aunque estas empresas han creado capacidad para acopiar hasta 30,000 quintales de maíz, desaprovechan la oportunidad para convertirse en un gran distribuidor, usando sus bodegas como la base de una serie de canales de distribución; así podrían pasar de ser empresas retenedoras a empresas proveedoras, pero ninguna de ellas se ve jugando este rol.

Hay oportunidades para reorganizar el mercado de los granos. No se tiene que seguir vendiendo por volumen y a mayoristas que sacan el maíz fuera del departamento o del país. ¿Por qué no pensar en ser proveedores de una red de tortillerías en las principales ciudades, o de las granjas avícolas, o de los supermercados con elotes, chilotes, maíz tierno enlatado o embolsado? ¿O por qué no estimular el procesamiento del maíz en otros productos, abriendo posibilidades de generación de otras iniciativas para otra gente que no tiene más opción que emigrar?

Hay mercado para el maíz en sus diferentes modalidades y siempre lo habrá. Sin embargo, La pregunta es: ¿́por qué las empresas retenedoras de granos se quedan en las bodegas? Algunos factores que contribuyen a explicar este fenómeno son:

1. Los productores trasladan su visión productivista a la empresa e inhiben su desarrollo empresarial. Por tanto, es fundamental un cambio de esquema mental y dejar que la empresa siga la dinámica del mercado. Implica abandonar unas ideas y ser receptivos a otras, incluyendo las que fueron rechazadas anteriormente. Veamos qué ideas condicionan la actitud del productor. 
En primera instancia, los pequeños productores parceleros ${ }^{11}$ de San Dionisio en Matagalpa o Jalapa, se perciben de manera negativa como productores de alimentos frente a otros estratos sociales, con lo cual crean una subjetividad que influye en la dinámica de las empresas. Ser productor de granos es percibido como una actividad de poco valor "nosotros nos penqueamos, dejamos la vida entera porque lo que hacemos es trabajo como de animales” (Téllez T.) Percepción que muchas veces es reforzada por acciones y declaraciones institucionales: sembrar granos básicos no es rentable, con la consecuente eliminación de créditos.

O por otro lado, los productores ven a los comerciantes como sus enemigos. Piensan que viven a sus expensas, sin invertir el mismo esfuerzo, por lo que no se pueden establecer alianzas con ellos. "Nunca un comerciante va ha ser nuestro aliado. ¿Cuándo? Es mentira, si ellos sólo viven buscando como darle mazo ${ }^{12}$ a uno” (socio del banco de granos).

"Para el comerciante, el productor es su amigo cuando le va a comprar, porque necesita que le dé barato; pero se vuelve un enemigo cuando el productor necesita de él”. (Productor Samulalí). De esta manera, las ideas y percepciones se traducen en desconfianza y en sentimientos de inseguridad que se trasladan a las iniciativas empresariales.

2. La lógica de actuación de las empresas de productores difiere bastante de la que siguen los comerciantes, tanto en su estructuración como en su funcionamiento. El siguiente cuadro 12 resume ambas perspectivas.

Cuadro 12. La comercialización vista desde dos perspectivas diferentes

\begin{tabular}{|l|l|l|}
\hline $\begin{array}{l}\text { Elemento de } \\
\text { comparación }\end{array}$ & \multicolumn{1}{|c|}{ Intermediarios yComerciantes } & $\begin{array}{l}\text { Empresas retenedoras } \\
\text { de granos }\end{array}$ \\
\hline $\begin{array}{l}\text { Ub i c a c ión } \\
\text { física del } \\
\text { producto }\end{array}$ & $\begin{array}{l}\text { La mayoría de los comerciantes con bodegas están } \\
\text { concentrados en un área del mercado local en el pueblo } \\
\text { o ciudad. Están visibles, cuentan con teléfono, camiones } \\
\text { o camionetas y emplean como mínimo un ayudante en la } \\
\text { bodega-negocio. }\end{array}$ & $\begin{array}{l}\text { La bodega está distante del } \\
\text { mercado principal visible en } \\
\text { el departamento. Su función } \\
\text { es conservar el grano. }\end{array}$ \\
\hline $\begin{array}{l}\text { Momento de } \\
\text { las ventas }\end{array}$ & $\begin{array}{l}\text { La compra y venta de los granos es una actividad de } \\
\text { todos los días durante un periodo de 10 a 11 horas diarias: } \\
\text { abren a las 6:30 a.m. y cierran 5:30-6 p.m. }\end{array}$ & $\begin{array}{l}\text { La venta de los granos se da } \\
\text { una sola vez en el año. }\end{array}$ \\
\hline $\begin{array}{l}\text { Universo de } \\
\text { clientes }\end{array}$ & $\begin{array}{l}\text { Amplio yvariado, tanto por la vía del abastecimiento como } \\
\text { del consumo. Tienen clientes fijos y esporádicos, tanto } \\
\text { locales como externos. }\end{array}$ & $\begin{array}{l}\text { Restringido: En el año 2001, } \\
\text { vendieron a dos clientes y en } \\
\text { la venta más reciente del2002, } \\
\text { a mós de ocho } \\
\text { nomerciantes-intermediarios. }\end{array}$ \\
\hline $\begin{array}{l}\text { Relación con } \\
\text { los clientes }\end{array}$ & Diaria & $\begin{array}{l}\text { Esporádica. Sólo en el } \\
\text { momento en que se decidió } \\
\text { hacer la venta anual. }\end{array}$ \\
\hline
\end{tabular}


Los comerciantes de granos establecidos y reconocidos se subdividen en mayoristas (grandes y medianos) y minoristas. Su función es mercantil: compran y distribuyen el maíz y el resto de granos ${ }^{13}$ casi al mismo tiempo. Es un proceso que no se detiene durante el día, es un modo estable de trabajar y de vivir. Almacenan por poco tiempo y, al vender al por mayor, ganan por volumen obteniendo utilidades que van desde los cinco hasta los 30 córdobas por quintal (entre 0.34 y 2.07 dólares). Compran a quien les ofrece el producto pagando según la calidad y venden a cualquiera. A diferencia de la empresa de los productores, cuentan con clientes fijos y clientes esporádicos.

Las organizaciones externas aliadas de los productores y sus empresas también tienen una visión limitada a la esfera productiva. Sus enfoques se concentran en la finca, en elevar rendimientos productivos, diversificar o tecnificar la producción, atender otras necesidades sociales como sistemas de agua, educación, programas de letrinas y una variedad de acciones más, pero no en el mercado. Trabajan con enfoques participativos, género, medio ambiente, manejo y gestión de riesgos, pero no incorporar otros enfoques de trabajo que les permitan ver lo que hacen en el marco de la cadena de valor de los productos que cultivan las familias.

La orientación social de la mayoría de estas organizaciones no gubernamentales y su forma de concebir su rol las desliga del mercado. Muchas de sus acciones tienen lugar ignorando estos vínculos, aunque cotidianamente se relacionen de una u otra manera con ellos.

En consecuencia, productores y organizaciones coinciden en buscar formas de organización que, en el fondo, tienden a cerrarse en un micro mundo que busca romper con algunos esquemas, pero a la vez se queda atrapado, y por tanto, sin romper las fronteras de las construcciones sociales que les atan. Así, las oportunidades no se pueden ver desde adentro por las ideas y conceptos que subyacen en los individuos; y en las propias organizaciones, por los mitos que se tienen acerca de la actividad comercial.

\section{Conclusiones y recomendaciones}

Finalmente, ¿qué haría exitoso a un modelo de retención de granos para generar valor? Para dar respuesta a esta pregunta, resumamos brevemente lo ocurrido con estas iniciativas de comercialización de granos a partir de la retención, para luego enlistar los elementos y aspectos que necesitan ser desarrollados para su éxito.

1. Hasta ahora, las empresas han querido conquistar el éxito a base de obtener los mejores precios del mercado, pero la apuesta por el precio más alto no las ha llevado al desarrollo empresarial y a su capacidad competitiva.

Los productores y sus empresas tienen una idea muy simple del precio, porque ignoran lo que hay detrás: a) el precio es un referente de los atributos especiales de un producto ${ }^{14}$ b) los precios fluctúan frecuentemente en dependencia no sólo de la salida o ausencia de cosecha local, sino del movimiento que se hace del producto desde otros orígenes, incluyendo las importaciones; y c) el precio se forma en un proceso, a medida que se forma la cadena de valor del producto. 
2. Se parte del criterio de que retener los granos en una bodega grande, y disponer de recursos financieros para adelantar a los productores es clave para competir con los intermediarios; pero la experiencia muestra que aún teniendo ambos factores a favor, las empresas operan, pero no necesariamente de manera exitosa. Más difícil todavía es que logren competir realmente. La explicación para no conseguir éxito bajo este supuesto se encuentra en que solamente se ha trabajado en una dirección (la retención), dejando por fuera otros aspectos relevantes, como la construcción de relaciones en el mercado.

Uno de estos aspectos es su propia visión hacia el futuro, hacia dónde apuntan, sobre la base de qué relaciones estables necesitan desarrollar y con qué actores, durante la fase de la intermediación del producto. De momento, las empresas están solas, "peleadas" incluso con comerciantes, con poca información y conocimiento del comportamiento del mercado del producto, mientras los comerciantes de granos forman parte de redes de colaboración e información.

En su trayectoria, las empresas tienen prolongados períodos muertos, mientras los comerciantes, a lo sumo, descansan el domingo. En este sentido, la necesidad de cambiar el esquema de funcionamiento actual para hacer de la comercialización una actividad regular, es un reto importante.

3. La capacidad de incidencia en el mercado local presenta resultados duales: la UCOSD logra incidir en la regulación del precio al momento del acopio en las comunidades de su incidencia; las otras dos experiencias (Egranojal y Ecogranos), no tienen un efecto similar porque son prestadoras de servicios. Pero aún cuando la UCOSD logra generar este efecto positivo en sus comunidades asociadas, queda limitado a este espacio. De otros municipios cercanos sale hasta tres veces más maíz que el que produce San Dionisio, de manera que lo que ocurre en la localidad no incide en el espacio clave donde se concentra el maíz: el mercado de Guanuca.

Esto hace pensar que, para tener capacidad de incidencia en el mercado de los granos, se necesita multiplicar la experiencia del banco en una versión, corregida y aumentada, en otros municipios que son grandes productores de maíz, y crear una red que articule estas iniciativas, donde cada una tenga una función complementaria de las otras. Sólo así se podrá incidir en la reorganización del mercado.

En este sentido, el crecimiento de la organización debería plantearse, no tanto mediante la integración de más socios al Banco de la UCOSD, sino haciendo surgir "Bancos hermanos" (multiplicación) y, en su conjunto, crear la sinergia necesaria para competir con los intermediarios o simplemente, para no competir con ellos ${ }^{15}$.

4. Hay poca práctica de las organizaciones y de sus empresas para ajustarse periódicamente a la realidad. Estos ajustes son producto de una mente abierta que analiza constantemente el entorno, el rol de la empresa y su eficiencia para cumplir su propósito. Las organizaciones ven hacia adentro y no hacia el entorno en el que se ubican, lo que no les permite evaluarse en el contexto, identificar oportunidades y disponerse para aprovecharlas. 
La toma de decisiones internas es un proceso lento, y enfrenta limitaciones para abordar sus contradicciones, sus errores, corregir y avanzar. De los tres casos, la UCOSD presenta mejor nivel de organización interna entre gremio y empresa pero, aún así, el proceso de auto o inter-aprendizaje es más lento que la dinámica del mercado de granos, lo cual la pone en desventaja. El sentido de cuestionamiento crítico no siempre es bien recibido o bien visto, aunque lo resiste mejor que las otras iniciativas, dado que cuenta con un actor externo (Prodessa) que evalúa y presiona por cambios.

Ahora bien, ¿̇uáles son los factores para el éxito? He aquí algunos de los más relevantes:

a) Dado que el consumo de maíz va a continuar en el futuro, con tendencia a crecer más rápidamente que la producción misma, y ante la amenaza de importaciones, las empresas necesitan realizar una metamorfosis, pasando de ser retenedoras a proveedoras de materia prima especializada o de productos ya procesados a otros actores de la cadena de valor del maíz. Un factor de éxito es el análisis frecuente del entorno, para evaluar la posición de la empresa y tomar las medidas de prevención y ajustes necesarios.

Si se asume que el éxito es producto de la combinación de las oportunidades con las fortalezas ${ }^{16}$ se encuentran muchas posibilidades de conseguirlo, pero implica desarrollar, a lo interno de las empresas, una visión sobre las oportunidades y sus tendencias, así como diseñar una estrategia adecuada para su aprovechamiento. El acompañamiento de organizaciones externas con capacidad de crear o desarrollar mentalidades visionarias es una necesidad que las empresas deben satisfacer.

b) Es necesario desarrollar la capacidad de aprender, desaprender y aprender a perfilar el entorno y las tendencias del mercado de granos y de los sub productos del maíz, para reducir desventajas actuales, en la medida en que se superan las debilidades internas de las empresas y de la organización en sus relaciones comerciales. En este proceso de aprender y desaprender, es necesario que tanto el gremio como la empresa participan, cada uno desde su propia perspectiva, para definir claramente las nuevas reglas del juego.

c) Las empresas necesitan incorporar nuevos enfoques y métodos auxiliares para sus decisiones. Ente ellos, el concepto de cadena de valor, como herramienta que permite visualizar los diferentes eslabones que recorren los granos desde que se toma la decisión de producir (diseño del producto), hasta que son llevados a los consumidores finales. Aunque bastante reciente en el país, entender su lógica y dinámica ayudaría a ampliar las perspectivas de las empresas. Un proceso de acompañamiento y capacitación en este sentido, es relevante.

d) Se necesita separar las funciones entre la empresa, cuya función es comercializar, y el gremio que la organizó, que además busca otro tipo de beneficios sociales que la empresa no podrá dar. Cuando las funciones están claramente definidas, se evitan tensiones, críticas o actos de oportunismo que deslegitiman a la empresa y a su organización. Las empresas necesitan operar como cualquier empresa comercial que busca utilidades. En la medida en que operen de manera transparente para sus 
asociados, disminuirán el temor y la desconfianza de que se mal utilicen los recursos o de que sirvan para propósitos particulares.

En definitiva, el factor clave es el desarrollo del capital social basado en ampliación y construcción de un nuevo conocimiento que permita definir las estrategias, a partir de las potencialidades y capacidades disponibles.

\section{Notas}

2 Encuesta realizada por el IMC en el marco del estudio El aporte económico de la mujer al desarrollo de la Región Las Segovias.

3 No existen datos de este tipo de productos tanto en producción como en consumo.

4 Cortado al mes de octubre de 2000 en Mercado Oriental y Mercado Mayoreo en Managua.

5 Precios de la primera semana de enero de 2003.

6 En el caso de Jalapa, la producción se junta con la de Quilalí y el Jícaro, todos municipios del departamento de Nueva Segovia de donde se obtienen unos 436,000 quintales de granos que pasan por los comerciantes de Ocotal, Somoto y Estelí que, a su vez, están conectados con otros comerciantes del Pacífico y Occidente.

587 La capacitación se centra básicamente en la estructura organizativa, en el manejo de la bodega y en la administración de los recursos, que es necesaria, pero insuficiente para colocarse bien en el mercado.

8 Estos otros espacios complementarios para resolver otras necesidades son, por ejemplo, el banco de tierra, un programa de vivienda y el banco de crédito, entre otros. Cada uno de estos programas funcionan organizando asociados. De tal manera que un mismo productor puede estar en dos o tres programas a la vez, pero responde por separado a cada programa.

9 Algunos conflictos tienen que ver con el hecho de que los productores medianos al usar el trillo para procesar su producto, necesitan hasta dos semanas por su volumen de cosecha. En este periodo, los socios que cultivan menos área no pueden usar el servicio de trillado.

10 La venta de elotes en época de apante y verano adquiere mayor valor en el mercado en comparación con el maíz seco. Los elotes se venden por unidades o cienes que se cotizan entre C $\$ 0.50$ y C $\$ 0.85$ la unidad desde la parcela, triplicando el valor del maíz seco. Lo mismo ocurre con la venta de chilotes en época de apante y verano, que se vende por docena a un precio promedio de 2.50 córdobas con segmentos variados de mercado: industria de encurtidos, restaurantes, comiderías, supermercados y mercados populares.

11 La parcela es una expresión del minifundio que, por su reducida extensión, no puede ser objeto de sí misma en condiciones remuneradas.

12 Mazo se entiende como engañarle para llevarse la mejor ganancia.

13 Normalmente junto al maíz, compran y venden frijoles de diferentes variedades, café pergamino, cacao y achiote.

14 La calidad del producto, la forma en que se presenta, el olor, el color, el tamaño, etc., son factores que las empresas no consideran para sus procesos de comercialización.

15 Hay quienes opinan que es mejor no competir, lo cual implica buscar ser el único que ofrece o entrega un producto o un servicio especial que nadie más lo da, por lo tanto no hay con quien competir, la competencia vendrá después cuando alguien haya imitado el producto o servicio prestado, pero el reto de la empresa sería no dejarse equiparar o copiar.

16. Las empresas actuales tienen peldaños avanzados: cuentan con una base de asociados que necesitan fortalecer internamente y que le dan una razón de ser; disponen de infraestructura, capital de trabajo, personas con experiencia en el acopio, almacenamiento y control de la calidad del grano. También tienen un tipo de aliados claves (con excepción de EGRANOJAL), que le ayudan en los procesos de gestión, administración, toma de decisiones, pero adolece de otros aliados claves en el comercio. Necesitan diferenciarse del resto de los productores de maíz y tejer sus propias redes, al igual que lo hacen los comerciantes para distribuir los productos a diferentes segmentos de mercados, incluyendo los que están fuera del país.

\section{Referencias bibliográficas}

-ALVARADO, F. y RIVERA, J. (2003). El comercio de la rosquilla desde una perspectiva socio organizativa, Monografía. Facultad de Humanidades, Universidad Centroamericana. 
-AYALA, E. (1999). Instituciones y economía, una introducción al neoinstitucionalismo, Fondo de Cultura Económica, México.

-CURN-Estelí-Adeso Las Segovias, (2002). Situación actual de la micro, pequeña y mediana industria de alimentos del municipio de Esteli y sus perspectivas de desarrollo.

-IMC (2003). Base de datos del estudio: el aporte económico de las mujeres al desarrollo de la región Las Segovias. Caso departamenteo de Estelí. Documento interno.

-KAPLINSKY y MORRIS (2000). Handbook for Chain análisis (en línea), preparado para el IDRC (septiembre). Disponible en: http://www.ids.ac.uk/ids/global/pdfs/vchnov01.pdf -IMC (2002). Base de datos del estudio el aporte económico de las mujeres al desarrollo de la región Las Segovias, caso departamento Esteli.

- KARLHEINZ, W. y HEGE, M. (1997). Acción socioeducativa, modelos, métodos y técnicas. Madrid, Editorial Narzea S.A.

-MENDOZA, R., (2002).¿Qué hay detrás del bosque? El rol de los individuos y las estructuras sociales. Borrador preliminar Nitlapán-UCA. Documento interno.

-MAG-FOR (2002). Política para el sector agropecuario ciclo productivo 2002-2003, Nicaragua

-NORTH, D. (1993). Instituciones, cambio institucional y desempeño económico. Fondo de cultura económica, México. 